\title{
Clinical Psychology and Evolutionary Psychology: Toward a Dialogue
}

\author{
Richard J. Siegert \\ Victoria University of Wellington
}

\author{
Tony Ward \\ University of Melbourne
}

\begin{abstract}
The growth of evolutionary psychology as a theoretical framework for the study of human behavior has been spectacular. However, evolutionary psychology has been largely ignored by clinical psychology. This article is an attempt to encourage greater dialogue between the two. First, some of the major principles of evolutionary psychology are outlined, followed by consideration of some of the criticisms that have been made of this approach. Second, an attempt is made to trace the influence of evolutionary theory on the history and development of clinical psychology. Third, the authors describe how an evolutionary perspective has enhanced the understanding and study of autism and depression. Finally, some implications of an evolutionary perspective for etiological theory, assessment, treatment, and ethics are discussed.
\end{abstract}

Evolutionary psychology (EP) is a relatively new approach to the study of human cognition and behavior that argues that our evolutionary history provides the fundamental framework for developing theory and conducting research on human cognition and behavior. Evolutionary psychologists regard the human mind as an information-processing device that evolved over millions of years to meet specific environmental challenges. Thus, we can best begin to study human cognition and behavior with an understanding of the nature of the mind that is most likely to have evolved. The growth and development of EP as a theoretical framework for guiding the study of human behavior has been little short of spectacular (Barkow, Cosmides \& Tooby, 1992; Buss, 1999; Cosmides \& Tooby, 1989).

Richard J. Siegert, School of Psychology, Victoria University of Wellington, Wellington, New Zealand; Tony Ward, Department of Criminology, University of Melbourne, Melbourne, Victoria, Australia.

This article was completed while Richard J. Siegert was on research and study leave at the University of Melbourne. During this time he was a visiting fellow at the Department of Criminology of the University of Melbourne and also the resident scholar at St. Hilda's College, Parkville, Melbourne. He is very grateful to both for their collegiality and support in the writing of this article.

Correspondence concerning this article should be addressed to Richard J. Siegert, who is now at Rehabilitation Teaching and Research Unit, Department of Medicine, Wellington School of Medicine and Health Sciences, P.O. Box 7343, Wellington South, New Zealand. E-mail: Richard.Siegert@vuw.ac.nz
Since the early 1980s, EP has rapidly replaced its predecessor, sociobiology (E. O. Wilson, 1975), and has become a powerful paradigm for generating theory and research regarding such varied phenomena as language (Pinker, 1997), pregnancy sickness (Profet, 1992), theory of mind and "mentalizing" abilities in humans (Baron-Cohen, 1995), mate selection (Buss \& Schmitt, 1993), stepparenting and marital conflict (Daly, Singh, \& Wilson, 1993), and rape (Thornhill \& Palmer, 2000). Sociobiology was the first systematic attempt to apply the understandings of modern evolutionary biology to explain human behavior (E. O. Wilson, 1975). Its arrival met with enormous controversy owing to its supposedly extreme "biological determinism," and a role for evolutionary factors in human behavior had few strong advocates until the development of EP (Ruse, 1985; Sterelny \& Griffiths, 1999; Tooby \& Cosmides, 1992). The major difference between the two approaches is that sociobiology concentrated on the selection of behaviors, and social behavior in particular, whereas evolutionary psychologists assume a broader brief and favor the selection of a smaller number of cognitive mechanisms or modules. EP's strengths include its solid grounding in evolutionary biology, which provides a unifying theory for understanding the behavior of organisms, and also the ability of the resulting theory to generate testable predictions concerning a variety of human behaviors. A basis in evolutionary biology 
means that EP shares the same scientific foundations as all other disciplines that study living organisms.

Despite the rapid rise in popularity of EP in recent decades, it is our impression that its impact on the field of clinical psychology (CP) has been minimal. For example, in a PsycLIT search for the years 1989-1999 using the key words evolution (and, alternatively, evolutionary), clinical, and psychology, we found only five references, none of which concerned evolutionary theory and $\mathrm{CP}$ but rather were concerned with the evolution of the profession. A search for evolutionary psychopathology produced two relevant references.

In this vein, the present article represents an attempt to encourage greater dialogue between the two disciplines with the expectation that both will benefit. We begin by outlining some of the major principles of EP, and then we consider some important criticisms that have been made of EP. Next, we attempt to trace the influences of evolutionary theory that are most evident in the history and development of CP. It is our contention that EP has had little influence on $\mathrm{CP}$ to date and that $\mathrm{CP}$ stands to gain considerably by a closer theoretical integration. To substantiate this claim, we then describe how in the neighboring field now known as evolutionary psychopathology, an evolutionary perspective has enhanced the understanding and study of both autism and depression. Finally, we discuss some implications of an evolutionary perspective on CP for etiological theory, assessment, treatment, and ethics.

\section{What Is EP?}

EP is first and foremost an approach to studying human cognition and behavior, and not a content area such as visual perception, reasoning, memory, or social interaction. It is, then, "a way of thinking about psychology that can be applied to any topic within it" (Cosmides \& Tooby, 2000, p. 1). The EP approach to understanding the mind can best be described by contrasting it with the dominant alternative paradigm in psychology, which Tooby and Cosmides (1992) have referred to as the standard social science model (SSSM). This model of human behavior and cognition posits a brain that has evolved into a content-free, general purpose learning machine. ${ }^{1}$ At birth the mind is a virtual tabula rasa, waiting for culture to determine its adult mental organization. In this model, intergroup differences in cultural patterns are emphasized, whereas biological variables and individual differences are minimized or simply ignored.

As stated by Tooby and Cosmides (1992), the SSSM posits that "adult mental organization is socially determined" (p. 26). According to the SSSM, the proper study of human beings is in fact the study of culture. The proper role of psychology in the SSSM is the study of socialization, particularly "learning," because this focus provides an explication of the mechanisms by which cultural processes transmit their cognitive programs to the individual. Ironically, although securing a legitimate place for psychology within the SSSM, this position has meant that psychology has abandoned the study of "human nature." Tooby and Cosmides commented that "the conclusion that human nature is an empty vessel, waiting to be filled by social processes, removed it as a legitimate and worthwhile object of study" (p. 29). In contrast to the SSSM, an EP approach to the study of the human mind and human nature strongly disputes the notion of the human mind-brain as a general learning or problem-solving device. However, it is just such a model of a generalized information-processing device devoid of evolutionary influences that has dominated cognitive psychology for the past 30 years.

Rather, evolutionary psychologists argue that millions of years of evolution provided specific environmental challenges that have resulted in specific cognitive mechanisms designed to meet those challenges, through the processes of natural selection and sexual selection. Thus, our minds and their information-processing mechanisms are just as much products of the evolutionary process as our bodies. Moreover, the processes of natural selection and sexual selection will determine a species' cognitive architecture just as they have determined its wing

\footnotetext{
${ }^{1}$ The SSSM, as described by Cosmides and Tooby, is admittedly an extreme version that allows little room for the role of biological factors. In this sense, it may not be entirely representative of the models that are currently popular in CP (e.g., the biopsychosocial model). However, for the purposes of illustrating the exact nature of EP, Cosmides and Tooby argued that it is most informative to contrast EP with what it is not (i.e., the SSSM).
} 
span or temperature regulatory mechanisms. As a consequence, the newborn human brain is anything but a general learning device that is programmed by culture.

Rather, the mind is believed to be a set of specialized content-rich, domain-specific mental modules (Fodor, 1983; Hirschfeld \& Gelman, 1994) that operate independently but in a coordinated fashion. To use Tooby and Cosmides's vivid metaphor, the mind is more like a Swiss army knife than a computer operating with a few general purpose programs. Our brains are constituted out of numerous specialized, domain-specific information-processing mechanisms that have evolved to solve different adaptive problems (Tooby \& Cosmides, 1992). Such modules are considered to be independent, selfcontained information processors that function quickly and automatically and mostly outside of conscious awareness. Tooby and Cosmides (1992, p. 90) posited modules for mate selection, language acquisition, family relationships, and cooperation, as well as a "belief-desire folk psychology-a so-called theory of mind."

Each of these modules represents an adaptation that has evolved to solve a specific problem facing our ancestors, such as avoiding predators, forming friendships and alliances, selecting mates, and communicating with others. Failure to solve these problems satisfactorily would have lessened an individual's chances of surviving and passing on his or her genes to future generations. Modules are psychological structures or information-processing mechanisms that operate according to specific rules in certain domains, and only when exposed to quite specific information. For example, a predator-avoidance module would function to detect designated predators and instruct individuals to adopt certain strategies to avoid or escape from them. Or a mate selection module would help males and females maximize their chances of finding a suitable mate and producing offspring that survived.

Adaptations are not easily identified, and evolutionary psychologists use a number of methodological rules to help them do so in a reliable and valid way (Tooby \& Cosmides, 1992). These include (a) demonstrating that the trait in question has design features that appear to solve an adaptive problem, (b) demonstrating that these features are unlikely to have risen by chance alone, and (c) demonstrating that they are plausibly the product of a module rather than being the by-product of another module designed to solve a different adaptive problem. In addition, the module or mechanism in question should develop reliably and efficiently in all human beings unless linked to a subgroup (e.g., gender-related adaptations). Thus, according to evolutionary psychologists, it is these modules or information-processing mechanisms that are selected for, rather than specific behaviors.

It is also important to note that these inherited mechanisms are not necessarily operating at birth. In fact, they may come "on line" at different developmental stages. So, for example, mate selection modules only really start to exert a profound influence during adolescence. In addition, modules are only activated once the relevant environmental conditions obtain and specific information is available as input to the mechanism. The nature of these inputs may also channel individuals down one of several possible developmental pathways by virtue of the effect on the relevant mechanism. For example, the absence of a father during childhood may result in a male adopting short-term mating strategies and not investing in a permanent relationship (Malamuth \& Heilman, 1998). Or being exposed to different levels of "mind talk" may cause individuals to develop different theories of mind (Ward, Keenan, \& Hudson, 2000). In a sense, environmental events serve to activate a mechanism and to calibrate it, thereby setting its threshold of activation and the particular form it takes.

As stated, not all human capacities are the result of adaptations (Buss, 1999). Whereas some traits have been selected for their capacity to solve problems faced by our ancestors, thereby increasing their chances of reproductive success and survival, others are probably byproducts of selected mechanisms or simply represent "noise" or random effects created by mutations or environmental changes. For example, whereas the ability to develop and speak a language may be an adaptation, our capacity to write is likely to be a by-product of the mechanisms generating speech. An example of a physical characteristic produced by "noise" is the particular shape of a person's belly button (Buss, 1999).

There are two major forms of evolutionary explanations of human traits, ultimate and prox- 
imate. Ultimate explanations attempt to identify the function of a given trait or mechanism by determining its role in solving a particular adaptive problem, whereas proximate explanations focus on the nature of the causal mechanisms that underpin its functional role (Buss, 1999). An important strength of EP is that it explains behavior in terms of both ultimate and proximate causes. ${ }^{2}$ In the language of EP, ultimate refers to all of the evolutionary factors that contribute to the development of a psychological mechanism or pattern of behavior. By contrast, proximate refers to the more recent factors involved. Thus, ultimate causes will include such features as the ancestral environment, sexual selection, and natural selection. Proximate causes will include such variables as genes, developmental history, learning, and environmental stimuli.

Symons (1979) commented that ultimate causes explain why an animal exhibits a specific behavior pattern; in ancestral environments, that behavior pattern promoted the reproductive success of the individuals displaying it. Proximate causes, according to Symons, explain how animals eventually develop and display specific behavior patterns. Thus, given a certain genetic endowment, the right developmental circumstances, and appropriate contingencies of reinforcement, the pattern of behavior will emerge. Moreover, any comprehensive explanation of a pattern of behavior should invoke both ultimate and proximate causes and suggest how proximate causes might activate the relevant mental mechanisms involved. Consequently, only EP, through its consideration of both ultimate and proximate causes, can provide a comprehensive explanation of patterns of human behavior.

There is converging evidence for the plausibility of EP from a number of sources. Philosopher Jerry Fodor, in The Modularity of Mind (1983), made a convincing case that at least the perceptual or input systems in the brain show a high degree of modularity. For example, the visual system is organized in a highly modular fashion (e.g., Marr, 1982; Zeki, 1993). Similarly, evidence from neuropsychology (particularly the methodology of double dissociation in patients) suggests that the human brain has evolved a highly modular architecture (e.g., Le Doux, 1998; McCarthy \& Warrington, 1990; Shallice, 1988). Research from cognitive anthropology suggests that there are indeed many "universal" features of behavior across cultures that indicate a common evolutionary history. Support also comes from questionnaire research wherein the EP approach has demonstrated powerful predictive ability on a range of issues relating to social and personality psychology (see Buss, 1999, for an overview). The EP approach, moreover, argues that the typical environment with which human minds evolved to contend is very different from that of modern Western society. As stated by Cosmides and Tooby (2000);

The environment that humans-and, therefore, human
minds-evolved in was very different from our mod-
ern environment. Our ancestors spent well over $99 \%$ of
our species' evolutionary history living in hunter-gath-
erer societies. That means that our forebearers lived in
small, nomadic bands of a few dozen individuals who
got all of their food each day by gathering plants or
by hunting animals... Generation after generation,
for 10 million years, natural selection slowly sculpted
the human brain, favoring circuitry that was good at
solving the day-to-day problems of our hunter-gatherer
ancestors-problems like finding mates, hunting ani-
mals, gathering plant foods, negotiating with friends,
defending ourselves against aggression, raising chil-
dren, choosing a good habitat, and so on. Those whose
circuits were better designed for solving these prob-
lems left more children, and we are descended from
them. (p. 13)

Finally, it is important to appreciate that modern versions of EP do not share some of the problems evident in sociobiology or earlier versions (Buss, 1999). First, EP should not be confused with genetic determinism or the view that behavior is rigidly determined by our genes with no input from the environment. Second, simply because a mental mechanism and the subsequent behavior it generates are the products of natural selection (or by-products), this does not mean we are unable to modify our

\footnotetext{
${ }^{2}$ Sterelny and Griffiths (1999, p. 19) cited Tinbergen (1963), who distinguished among four kinds of explanations in the evolutionary analysis of behavior: "(1) the evolutionary history of a behavior; (2) the current use of the behavior in the life of the animal, which may involve a change from (1); (3) the development of the behavior over the life of the organism; (4) the psychological and other mechanisms used in the control of the behavior." A fully comprehensive explanation of behavior would ideally explain behavior at all four levels. Sterelny and Griffiths speculated that evolutionary theorists and social scientists may be engaged in "different explanatory projects." This might account for some of the traditional hostility between the two approaches. However, we argue that a comprehensive explanation must embrace both.
} 
actions. Psychological mechanisms are activated by information in the environment, and the form they take is directly influenced by the nature of this information. Therefore, changing the content or meaning of such information may result in quite different beliefs, desires, goals, and behavior.

Third, the fact that our minds and bodies are the products of evolution does not mean that they are perfectly designed. The process of evolution involves trade-offs and constraints. Our minds are arguably the product of small changes over time, each of which is constrained by the effects of earlier changes. Gilbert (1998a) captured this ad hoc development nicely: "Evolution is an incremental process. Only small changes that 'tinker' with the current design are possible" (p. 355). Finally, we do not consciously or unconsciously attempt to maximize our gene reproduction. Our motives and goals are partially the result of psychological mechanisms selected for their capacity to improve our ancestors' survival and reproductive success; with a few rare exceptions, they do not lead us to intentionally engage in actions that we believe will result in our genes being passed on to a new generation. The fact that this may occur as a consequence of our actions is fortuitous rather than intentional.

\section{Criticisms of EP}

\section{Is EP Reductionist?}

Like their sociobiological predecessors, evolutionary psychologists have been accused of reductionism (H. Rose \& Rose, 2000; M. R. Rose, 1998). Reductionism is an essential strategy for understanding complex phenomena in most branches of science. It refers to a process whereby complex phenomena are broken down into components, which are then divided into subcomponents for analytic purposes. The epistemological assumption at work here is that we can best understand how an entire system works if we can first understand how each of its parts works separately (Nagel, 1998).

Critics of reductionism, as applied to human behavior, typically invoke the notion that different levels of explanation are appropriate for explaining behavior at different levels of organization. M. R. Rose (1998, p. 178) put it thus: "Each level of complexity of nature involves new interactions and relationships between the component parts which cannot be inferred simply by taking the system to pieces." Implicit in such criticisms is the idea that certain explanatory variables or causal mechanisms may only emerge (i.e., come into existence) at a specific level.

Critics of EP argue that it attempts to reduce complex human behaviors that are multiply determined to the effects of a set of genetically programmed modules that operate without regard to developmental history, contextual factors, or cultural influences, ignoring the fact that evolutionary psychologists are quick to affirm the importance of studying both proximate and ultimate causes of behavior. A comprehensive explanation of any human phenomenon is likely to be multifactorial in nature and involve a variety of different causal mechanisms. These may include factors associated with our early evolutionary history as well as cultural, developmental, physiological, and psychological causal mechanisms. Each of these domains arguably represents a distinct level of analysis and offers a unique contribution to the understanding of human behavior.

Where the accusations of reductionism ring true, in our opinion, is in the tendency of evolutionary psychologists to sometimes pay lip service to the important role of proximate mechanisms without ever really specifying their form or how they relate to ultimate causes. For example, Thornhill and Palmer (2000) have advanced an evolutionary theory to explain rape in which they outline two possible types of evolutionary theories of rape. The first perspective stipulates that rape is directly selected for and represents an adaptation; a number of possible mechanisms are considered and rejected. The second possibility is based on the assumption that rape is a by-product of other adaptations and essentially rests on Symons's thesis that the adaptation in question is associated with males' intense sexual drives and tendency to engage in impersonal sex.

What is missing in such a theory is any clear explication of the role of proximate factors such as adversarial attitudes toward women, poor conflict resolution skills, lack of intimacy skills, insecure attachment, mood regulation deficits, and deviant sexual fantasies, which are all examples of causal mechanisms that have been linked to rape (Polaschek, Ward, \& Hudson, 
1997). The mechanisms (proximate) in each of these distinct domains exert their own causal influence and should not be ignored or minimized.

What this line of criticism suggests is that although evolutionary explanations may help to identify the function of a trait, they do not specify the relevant causal mechanisms in sufficient detail. This is the job of proximate theories focusing on a number of different, but equally important, factors. Unless evolutionary explanations of behavior specify proximate as well as ultimate mechanisms, they leave themselves open to accusations of reductionism.

\section{Modularity Versus a General Purpose Learning Device}

One of the strongest contentions of Tooby and Cosmides (1992), Pinker (1997), and other proponents of EP is that the human mind is not a general purpose learning device programmed by experience, environment, or culture. Rather, the mind is composed of a number of specialized systems that have evolved to solve specific evolutionary problems such as finding a mate, rearing children, finding food, and living in groups. The issue of modularity is an empirical one, however, and there exists a wide range of opinion as to how well this concept fits with our knowledge of human minds and their evolutionary past. We briefly mention three alternative viewpoints from three quite different domains: developmental psychology, neurobiology, and archaeology.

Karmiloff-Smith (1992, 2000) has argued that modular conceptions of the mind are not well supported by observations and research on the development of cognition in children and that when there is good evidence for modular functions they can be accounted for by developmental processes. She has suggested that cognitive specialization might be the "product of child development, not its starting point," noting that "domain-specific outcomes do not necessarily entail domain-specific origins" (Karmiloff-Smith, 2000, p. 147).

From a quite different perspective, neurobiologist Terrence Deacon (1997) has recently disputed the existence of the prototypal module, Chomsky's language acquisition device (LAD). Deacon has argued that Chomsky's LAD is what evolutionary biologists refer to as a "hope- ful monster" theory. That is, in the absence of any strong evidence as to how language evolved, and unable to explain the ease with which virtually all young humans quickly learn to speak in grammatically well-formed sentences, we imagine a "freak mutation" that "just happens to produce a . . . better equipped organism" (Deacon, 1997, p. 35). In this case it is an LAD, a modular "language organ" that somehow carries the "universal grammar" said by Chomsky to underlie all human languages. Deacon has also disputed Chomsky's famous claim that grammar is unlearnable, noting that recent work with neural networks has shown how quite simple networks can rapidly acquire grammatical rules. Deacon's own theory of the evolution of language and the brain does not involve a modular architecture.

Archaeologist Steven Mithen (1996) has proposed an evolutionary prehistory in which our earliest ancestors' minds were characterized by general intelligence. This mind then evolved modules for specific domains, such as technical and social intelligence, and these modules evolved to become more permeable. In his book The Prehistory of the Mind, Mithen noted that the challenge for proponents of a modular viewpoint is how to explain our modern mind's most striking characteristic, its "capacity for an almost unlimited imagination" (1996, p. 10). Mithen attempted to do this himself by integrating archaeology and cognitive psychology in a hybrid discipline he called "cognitive archaeology." He argued that "the critical step in the evolution of the modern mind was the switch from a mind designed like a Swiss army knife to one with cognitive fluidity.... This enabled people to design complex tools, to create art and believe in religious ideologies" (Mithen, 1996, p. 223). Moreover, according to Mithen, we can date this transition to "between 100,000 and 30,000 years ago" (p. 223).

In summary, it is a central thesis of EP that the mind functions not as a generalized learning device but, rather, as a set of specialized modules, the so-called Swiss army knife model. However, this argument remains just that, an argument. There is sufficient evidence from developmental psychology, neurobiology, and archaeology for us to say that the jury is still out on the question of modularity and that several equally plausible alternatives exist. 


\section{Is EP Bad Science?}

There are a number of points on which critics like to cast doubt on the scientific status of EP. We consider only one of the more frequent and serious criticisms: that evolutionary psychologists are guilty of telling "just so" stories. This expression is borrowed from the name given to Rudyard Kipling's imaginative children's fables (e.g., "How the Leopard Got His Spots" and "How the Camel Got His Hump"). When applied to EP explanations, it refers to the ease with which one can hypothesize adaptationist scenarios about the life of a hunter-gatherer on the African savanna during the Pleistocene period (in fact, Michael Rose used the label "Savanna stories").

Certainly, evolutionary psychologists consider themselves to be participants in what biologists have called the "adaptationist program" (Symons, 1992). The adaptationist program is concerned with determining the function of a particular structure or organ by asking what problem or problems it evolved to solve. Symons (1992, p. 141) talked about the "adaptationist question": "Was trait X per se designed by selection to serve some function; i.e. is it an adaptation?" The most commonly cited example is the eye; a careful examination of its structure strongly suggests that it has clearly evolved for the purpose of sight. An important issue for the credibility of EP is just how one can distinguish a sound adaptationist analysis from a well-told "just so" story. Pinker (1997) referred to this process as "reverse engineering."

According to Tooby and Cosmides (1992), we can avoid telling just so stories by first conducting an "evolutionary functional analysis," a process that, they stated, involves five steps.

1. An adaptive target: The issue here is to identify a recurring problem that must have faced our ancestors in their hunter-gatherer past, such as which plants are safe to eat, how to choose a good mate, and who to form an alliance with against enemies. Tooby and Cosmides (1992, p. 73) noted that "the goal is to ascertain whether the proposed behavioral outcome... will enhance design propagation under ancestral conditions."

2. Background conditions: This step entails a careful consideration of the likely environmen- tal conditions prevailing in the ancestral environment. This environment includes not only the external physical environment but also features of human anatomy and physiology. Clearly, this will involve conjecture, but Tooby and Cosmides suggested that detailed knowledge of the lives of modern hunter-gatherers, as well as paleoanthropological evidence, provides a firm basis. The key question here is as follows: "What features of the ancestral world were sufficiently stable to support the evolution of a design that could produce an adaptive target[?]" (Tooby \& Cosmides, 1992, p. 73).

3. A design: Here the process involves specification of the design features of an information-processing mechanism that can solve the problem raised in Step 1 in the ancestral environment of Step 2. Tooby and Cosmides noted that in many cases the mechanism is unknown, and consequently this step actually involves constructing a hypothesis about the design features of such an adaptation and then specifying, in information-processing terms, exactly how it would function.

4. A performance examination: In Step 4 of the evolutionary functional analysis, one is attempting to provide a "description of what happens when the proposed adaptation mechanistically interacts with the world" (Tooby \& Cosmides, 1992, p. 74). An important point to bear in mind here is that the "world" at issue is the world of our ancestors, the so-called environment of evolutionary adaptation. It cannot be assumed that the adaptation will function the same or even be adaptive in the modern world. Thus, this stage may involve conjecture regarding the adaptation's performance in the ancestral environment but also how it might function under present-day conditions. The central issue here is what outcomes the mechanism generates or how the inputs translate into outputs.

5. A performance evaluation: Here the question of concern is how well the design performs under conditions similar to the environment of evolutionary adaptation (in solving the problem raised in Step 1).

Therefore, according to Tooby and Cosmides, it is possible to evaluate evolutionary theories concerning the architecture of the mind and its likely origins. However, it is clear that each of these five steps involves the formulation and evaluation of hypotheses. Thus, there is the risk that personal and scientific biases, a lack of 
critical scrutiny, and poor analysis may result in false conclusions and flawed theories. Furthermore, even if the process of formulating ideas and testing them is exemplary, mistakes are likely given the intangibles involved and the extreme difficulty in reconstructing past events and contexts. The preceding criticisms pose important challenges to $\mathrm{EP}$, and debate still rages concerning its theoretical and empirical status. However, we suggest that despite these problems, it constitutes an extremely promising approach to the study and explanation of human behavior and merits further critical discussion and investigation.

\section{The Evolution of CP and the Theory of Evolution}

The birth date of CP is traditionally taken as 1896, when Lightner Witmer founded the first psychological clinic at the University of Pennsylvania (Nietzel, Bernstein, \& Milich, 1998). This event occurred only 17 years after Wundt had begun the first psychological laboratory at the University of Leipzig in 1879. Darwin, of course, had already published his first edition of The Origin of Species in 1859. Nietzel et al. (1998) noted that two fundamental ideas came out of that book: (a) that individual characteristics can vary both within and between species, including humans, and (b) that the process of natural selection acts upon these individual characteristics. In The Origin of Species, Darwin also devoted a chapter to the concept of instinct, drawing a distinction between instincts and habits. Brems, Thevenin, and Routh (1991) noted that Darwin's work had a profound effect and stimulated research on evolution and human behavior by addressing such issues as children's reflexes, criminology, and belief systems. His ideas were particularly influential on two important figures in the early history of CP: Frances Galton and Sigmund Freud.

\section{Darwin, Galton, and the Mental Testing Movement}

An idea central to Darwinian thinking was the notion of individual differences. Hergenhahn and Olson (1993, p. 43) commented that "individuality was appreciated as never before and its study became popular." The notion that in- dividual differences could be quantified and studied had a great impact on Darwin's cousin, Frances Galton, a pioneer of the mental testing movement. He was an innovator in the development of statistics and first described the concepts of correlation and regression to the mean (Hergenhahn, 1992). Galton also invented the questionnaire, first used the word association test, studied mental imagery, and started the first mental testing center (Hergenhahn, 1992; Nietzel et al., 1998). Regrettably, he was a pioneer in the eugenics movement as well, which sought to improve the human species through the application of "good breeding practices" (M. R. Rose, 1998). In Victorian England, the eugenics movement advocated the "fostering of reproduction among the talented and virtuous (i.e. the upper middle class), along with the imprisonment or sterilization of the habitually criminal or otherwise antisocial" (M. R. Rose, 1998, p. 135). The popularity of eugenics persisted long after Galton's demise, however, and the movement lent "scientific" support to racist U.S. immigration laws in the 1920 s, sterilization of the "feebleminded" in the United States well into the 1950s, and the Nazi party's own "medical eugenics" program (M. R. Rose, 1998).

In summary, Galton was directly influenced by Darwin's ideas, leading to his interest in the quantification and study of individual differences. As such, his work was a forerunner of modern psychometrics and personality theory. At the same time, his eugenics movement represents the "saddest and ugliest [episode] in the history of Darwinism" (M. R. Rose, 1998, p. 135). Indeed, Baron-Cohen (1997) has suggested that the eugenics movement, and its implication in the Nazi atrocities of the final solution, probably contributed to the relative neglect of evolutionary approaches that has characterized modern psychiatry until quite recently.

Meanwhile, interest in the measurement of individual differences grew, and psychological testing continued to develop and thrive. The work of J. M. Cattell in the United States, Binet and Simon in France, and Spearman in Great Britain resulted in psychological tests being a feature of everyday life in the 20th century. When the United States entered World War I in 1917, Robert Yerkes (at that time president of the American Psychological Association) was made an army major and given the task of devising tests for detecting "mental defectives" 
as well as those of special ability. By the end of 1919, when the program was terminated, some 1.75 million individuals had been tested (Hergenhahn, 1992). The notion of individual differences and the value of psychometric testing have remained core features of CP. This is perhaps the clearest influence of Darwin's revolution on the history and development of CP.

\section{Darwin's Influence on Freud}

Although Freud's theoretical legacy may increasingly be under attack by contemporary $\mathrm{CP}$ (Nietzel et al., 1998), it is difficult to deny the enormous influence of such essentially Freudian concepts as mental structure, unconscious processes, defense mechanisms, and developmental stages on clinical practice. Freud wrote his early works in the wake of Darwin, and Butler and Strupp (1991) noted that his training in medicine and neurology occurred at a time when Western scientific thinking was rapidly assimilating Darwinian ideas and concepts. Butler and Strupp also noted that central to Freud's thinking were the concepts of drives and instincts that stemmed from human evolutionary heritage. They commented that, "consistent with the Darwinian emphasis on individual and species survival, Freud envisioned these primitive, uncivilised wishes as reflecting survival needs such as thirst, hunger, elimination, and reproduction" (p. 520).

Hergenhahn (1992) observed that in demonstrating the continuity between humans and other animals, Darwin strengthened Freud's contention that human behavior was motivated by instincts rather than reason. In this regard, Freud had something in common with the evolutionary psychologists today who proclaim that "our modern skulls house a stone age mind" (Cosmides \& Tooby, 2000, p. 13). To summarize, Freud was influenced by evolutionary theory and regarded his own work as rooted in biology, but this Darwinian influence is probably best described as implicit in his theories.

\section{Darwin, Behaviorism, and Animal Models of Psychopathology}

Perhaps one reason for a decline in the influence of Darwinian evolutionary theory on CP in the early and mid-20th century was the rise of behaviorism. Of course, the very notion of behaviorism, with its emphasis on studying the behavior of rats and pigeons, rests on Darwinian assumptions. It is assumed that there is a continuity among species such that although each species has its own history of evolutionary adaptation, the different species share similar, if not identical, mechanisms of learning. Hence, the study of Pavlovian conditioning or operant conditioning in rats, pigeons, and humans is thought to yield general principles of learning that can be applied to different species. However, by the 1920s and 1930s, the growth of social science as an academic force (and widespread adoption of the SSSM) led to a reaction against Darwinian influences.

Hilgard (1987) described the growing influence of sociology as an academic discipline and, within psychology, the rise of behaviorism. There was a zeitgeist developing that embraced democracy and egalitarian values, emphasizing environmental determinants of behavior and eschewing heredity. In part, this trend may have been a reaction against the crudest early attempts to apply Darwin's ideas to social structure, such as Spencer's social Darwinism and Galton's eugenics movement (see Hergenhahn, 1992, for more details on these phenomena). Whatever the cause, there arose within behavioral psychology a strong attack on the concept of instinct. For example, Hilgard quoted Beach as follows: "The concept of instinct will disappear, to be replaced by scientifically valid and useful explanations" (Beach, as cited in Hilgard, 1987, p. 406). Hence, the growth of behaviorism, and its powerful influence on CP in both the United States and Great Britain, probably led to a decline in the influence of evolutionary theory on CP. With or without an evolutionary basis, however, CP was flourishing.

World War II had created a much increased demand for clinical psychologists. After the war, there was a large population of veterans requiring assessment and rehabilitation, new training programs for clinical psychologists were quickly set up, and clinical psychologists for the first time began to provide psychotherapy. The growth of behavior therapy in the 1950s and 1960s further reduced any influence of evolutionary ideas among clinicians. Behavior was learned and maintained by present-day contingencies of reinforcement, biological influences were minimized, and environmental 
determinism was emphasized (Hilgard, 1987). Moreover, although Freudian psychoanalysis remained a powerful force in North America, especially in psychiatry, the field had evolved into a rapidly growing panoply of different psychotherapies by the 1960s (Hilgard, 1987). Each of these therapies had their own theoretical basis, but they drew little or nothing at all from Darwin. Perhaps the only theoretical connection was in the broadest possible sense: evolution as the only alternative to supernatural accounts of our origins.

In summary, by the late 1960s the growth of behaviorism in psychology had reduced the influence of evolutionary theory on CP in favor of environmental determinism. At the same time, although psychoanalysis continued to be a powerful force among clinicians, there had been little or no development of the Darwinian influence evident in Freud's thinking, and a proliferation of newer psychotherapies did nothing to change that fact.

One more recent trend that may have made an evolutionary perspective more respectable in $\mathrm{CP}$ has been the renewed popularity of animal models of psychopathology since the early 1970s (Mineka \& Zinbarg, 1991). Since the time of Watson and Rayner (1920) and their famous experiment with Little Albert, learning principles have been used to explain the development of anxiety conditions as well as to treat them (e.g., Eysenck \& Rachman, 1965; Wolpe, 1958; Wolpe \& Lazarus, 1966). A problem with such models is that contrary to some behaviorist accounts of acquired fear, not all fears are equally conditionable. For example, phobias regarding snakes, insects, dogs, heights, blood, germs, tunnels, and water are relatively common. By contrast, phobias concerning fears of automobiles, electric sockets, power tools, and guns are rare. To account for this finding, Seligman (1971) invoked the notion of biological preparedness. This theory posits that phobias are indeed learned through classical conditioning but that certain fears that may have served some adaptive purpose in ancestral environments are more readily conditionable. A series of studies by Ohman and colleagues produced considerable support for this theory (e.g., see Ohman, 1986).

Seligman's notion of biological preparedness is probably one of the clearest examples of modern clinical theory concerning psychopa- thology that has an explicit basis in evolutionary theory. However, Menzies and Clarke (1995) recently provided a critique of Seligman's preparedness account of phobias and argued for an even stronger evolutionary formulation, which they called a "nonassociative account." In their review, they noted that there are many examples of fears observed among different species that are difficult to account for solely through associative learning. For example, they cited Sackett (1966), who demonstrated that infant rhesus monkeys that had been reared in isolation reacted fearfully to slides of threat displays from other monkeys. Given their rearing in isolation in a laboratory, it is difficult to see how their fear reaction to conspecifics could stem from aversive conditioning experiences.

Menzies and Clarke (1995) also cited Walk and Gibson's (1961) now classic research on the "visual cliff" experiment with human infants and a variety of other species. Their experiments strongly suggested that, in a variety of land-dwelling species, a fear of heights is largely innate. Menzies and Clarke noted that although more recent research has suggested that fear of the visual cliff may not emerge until self-produced locomotion has appeared, the essential findings hold up. That is, crawling seems important for the development of visuospatial and communication abilities, but it does not seem necessary for falls to have been experienced, as an associative model might indicate. In summary, Menzies and Clarke reviewed considerable evidence suggesting that, in the case of certain human fears, associative learning is not necessary for fear onset. Of particular relevance to the present discussion is that Menzies and Clarke actually discussed Darwin's own ideas about the origins of certain fears in children and explicitly described their own nonassociative account as "Darwinian." Such clear and explicit links to evolutionary theory are relatively scarce in the clinical literature.

Our discussion has concentrated on the influence of evolutionary theory on explanations of anxiety, particularly phobias. However, other examples of psychopathology in which animal models have made important contributions include depression (especially the "learned helplessness" model of Seligman and his coworkers), psychopathy (Mealey, 1995), and schizophrenia (see Mineka \& Zinbarg, 1991). In the preceding discussion, we attempted to trace the 
influence of Darwinian thinking on the history and development of $\mathrm{CP}$. We have seen that Darwin's ideas were fundamental to the study of individual differences and the growth of psychological testing. Both psychoanalysis and behaviorism were influenced by Darwin in their early development, but this influence waned as the two schools of thought became established. In recent years there has been an upsurge of interest in animal models of psychopathology, and this has contributed to a general interest in the way in which an evolutionary perspective might contribute to understanding of how psychological disorders develop. A historical perspective on learning theory approaches to anxiety showed how the early Darwinian influence declined for much of the 20th century but has recently been revived.

The present discussion focuses on $\mathrm{CP}$ and evolutionary theory, but, not surprisingly, a similar situation has been noted for the discipline of psychology in general. Durrant (1998) noted a decline in evolutionary thinking in general psychology from the early part of the 20th century and then a renewal of interest beginning in the 1960s. He stated that several factors were influential in its decline. The first was social, as it became associated with social Darwinism and the eugenics movement. The second factor was theoretical, as a growing number of psychologists came to view evolutionary explanations of behavior as narrow, limited, and lacking in explanatory breadth. A third factor was the rise of behaviorism, which decreed that both minds (be they animal or human minds) and instincts were not fit subjects for scientific study.

A similar situation has been observed in the history of psychiatry. McGuire and Troisi (1998, p. 36) commented that "psychiatry's interest in evolutionary ideas parallels that of the social sciences." They noted that there was minimal interest in evolutionary concepts in psychiatry in the period after World War I up until the early 1960s. They claimed that in that period there were fewer than three dozen papers and books that advocated an evolutionary perspective on psychiatric disorders. Two important events that rekindled interest in evolutionary theory in psychiatry were the publication of an evolutionary explanation of depression (Price, 1967) and the enormously influential work of Bowlby (1969). Bowlby argued that one could best understand patterns of infant attachment in terms of their evolutionary origins. He also studied separation anxiety, which was another example of a fear present in all infants from an early age, regardless of their individual learning history or cultural context.

The purpose of the preceding historical account of CP was to trace the influence of evolutionary theory on CP. Its influence is most clearly evident in the psychometric tradition within $\mathrm{CP}$, but also in the early development of the two most influential schools of therapeutic thought, psychoanalysis and behaviorism. Yet, with a few notable exceptions, such as Seligman's notion of biological preparedness, evolutionary theory functions largely as a background theory within psychology. It is rarely discussed in the texts of $\mathrm{CP}$, and yet it seems fundamental to a scientist-practitioner model of $\mathrm{CP}$.

Does this mean, then, that EP is important to CP but only in a very general, nonspecific sort of way? Perhaps it functions like the theory of gravity. Most clinical psychologists accept that the world is round and that there is an unseen force we call gravity that keeps our feet on the ground. However, in terms of our day-to-day clinical practice and research, we take gravity for granted and ignore the theoretical physics that explain it. Similarly, evolutionary theory is there in the background and yet seems largely irrelevant to our day-to-day practice.

Arguably, it may be that many clinicians would view the relevance of such distal factors as natural selection as insignificant, if not absurd, when judged against the relevance of such proximate factors as an individual's developmental history, personality, social skills, attachment style, and social support. Here we argue that such a viewpoint is both shortsighted and anti-science. It is also not in the best interests of $\mathrm{CP}$ or its clients. Rather, we believe that a closer dialogue between CP and EP could lead to new and more refined theories of psychopathology and more effective psychological therapies. This dialogue has already begun in psychiatry, which, as discussed previously, also largely ignored Darwinian ideas until quite recently (e.g., McGuire, Marks, Nesse, \& Troisi, 1992). However, before expanding on the implications and potential benefits of a synthesis of CP and EP, we outline some of the major developments in the new field of evolutionary psychopathology. These provide evidence of the potential advan- 
tages that CP might gain from rediscovering its Darwinian heritage. This is also an emerging field in which psychologists have been major contributors.

\section{Evolutionary Psychopathology: Insights on Autism and Depression}

Although the impact of EP on much of CP may be limited, there has been a surge of interest in the relevance of evolutionary theory for the study of psychopathology in general. This new synthesis is often called evolutionary psychopathology (e.g., Baron-Cohen, 1997; Gilbert, 1998a; McGuire \& Troisi, 1998). The rapid development of this new field of study is a powerful demonstration of how the evolutionary perspective can shed fresh light on long-standing problems in the behavioral sciences. We first summarize the essential features of evolutionary psychopathology and then illustrate its theoretical fertility by describing its application to the study of autism and depression.

\section{What Is Evolutionary Psychopathology?}

Evolutionary psychopathology is the application of evolutionary theory to conceptualizing, classifying, and determining the etiology of mental disorders. It is multidisciplinary in nature and draws on the methods and theories of evolutionary biology, developmental psychology and $\mathrm{CP}$, and psychiatry to offer a radically new perspective on mental disorders. A central feature of many psychological disorders is that the behaviors that cause the most distress frequently have a self-defeating or maladaptive quality. People with phobias avoid situations that they know rationally are not a danger to them, even when this avoidance may prevent them from advancing their career. People with schizophrenia hear voices that only they can hear, and these voices persistently criticize their behavior. People with depression become withdrawn and unable to make even simple decisions for themselves. Evolutionary psychopathology attempts to explain the etiology of such disorders by first considering which evolved psychological mechanisms might be involved.

Typically, in explaining these kinds of problems, we tend to assume that they represent the breakdown of a normal adaptive function (admittedly, another possibility exists, namely that the behaviors in question have been repeatedly reinforced and thus may be adaptive for the individual concerned). Gilbert (1998a) commented that "in the best Platonic traditions of medicine...p pathologies are alien to normal functioning" (p. 353). Perhaps the most recent influential example of this tradition has been Wakefield's conception of mental disorder as "harmful dysfunction." According to this definition, a mental disorder must have two features. First, there is a value term based on social norms. Second, "dysfunction" is "a scientific term referring to the failure of a mental mechanism to perform a natural function for which it was designed by evolution" (Wakefield, 1992, p. 373). According to Wakefield (1992), "dysfunction is a purely factual scientific concept" (p. 383).

Such a definition of mental disorder has several advantages over alternative approaches to defining mental disorder, as Wakefield has argued. However, we suggest that it is incorrect in assuming that there has necessarily been a breakdown or failure in some natural function or mechanism that arose through evolution. There is an implicit assumption that the adaptive mechanism must be advantageous and in the interests of the organism's health and survival. According to EP, this is one possible explanation but not the sole possibility.

Evolutionary psychopathology offers two alternative hypotheses. One is that the psychopathology may represent an adaptive mechanism that was previously adaptive under quite different conditions from our modern environment (as described subsequently). Another is that the psychopathology might only represent a byproduct or side effect of an adaptive mechanism, rather than the evolved mechanism itself.

Gilbert (1998a, p. 353) suggested that "many states that we label 'psychopathology' may represent the activation of [previously] adaptive strategies." This is certainly true for some of our evolved physiological mechanisms. For example, humans have a sensitive apparatus for detecting sugar in foods and an evolved taste preference for sweetness. No doubt this was a useful adaptation in prehistoric times, when sugar in ripe fruit was an important source of energy for hunter-gatherers; in modern urban society, however, our "sweet tooth" is a source 
of numerous health problems in the guise of obesity, dental cavities, diabetes, and so forth. Perhaps this is also true for some of the mental mechanisms that have evolved in humans. Gilbert (1998a, p. 356) commented that people developed social mechanisms for cooperation and concern for others in the context of small groups in which there were high levels of kinship and in which individuals lived for their entire life span. In such an environment, cheating could have been costly and a reputation for deception decidedly disadvantageous. By contrast, we now live mostly in huge groups of unrelated and anonymous individuals in which being overly trusting may make one highly vulnerable to exploitation.

As mentioned, the other evolutionary explanation for psychopathology is that it may represent a by-product of an evolved adaptive mechanism rather than the mechanism itself. Thus, it can be seen as analogous to the way that effective drugs can also have harmful side effects. For example, Symons (1979) suggested that rape may be a by-product of a number of evolved characteristics of male sexual behavior, including greater arousal to visual stimuli, greater autonomous sex drive, and a greater desire for varied sexual partners.

Evolutionary psychopathology is concerned with "what animals are designed to do" (Gilbert, 1998, p. 357). To understand how things go wrong, we need to first comprehend the conditions under which behavioral and psychological mechanisms evolved as adaptations that increased individuals' chances of replicating. This is made difficult by the fact that most human evolution took place over some 6 million years, during which our ancestors lived in small groups of hunter-gatherers, under environmental conditions totally different from those of today. Moreover, adaptations may appear to be inefficiently organized when they represent compromises between competing functional requirements. They are "trade-offs" between competing functions or demands on the organism (Gilbert, 1998a). Nesse and Williams (1997) described some of the diverse ways in which an adaptive cognitive mechanism might be implicated in any form of psychopathology:

Many psychiatric symptoms turn out not to be diseases themselves but defenses akin to fever and cough. Furthermore, many of the genes that predispose [one] to mental disorders are likely to have fitness benefits, many of the environmental factors that cause mental disorders are likely to be novel aspects of modern life, and many of the more unfortunate aspects of human psychology are not flaws but design compromises. (p. 3)

In summary, evolutionary psychopathology entails the application of evolutionary theory to conceptualizing, classifying, and determining the etiology of mental disorders. In beginning to understand the causes of a mental disorder, we must first be clear which adapted cognitive mechanisms are implicated in the psychopathology. However, we cannot simply infer that the disorder represents a breakdown of these adaptive mechanisms. We must also consider the possibility that it represents a functioning adaptive mechanism designed for the hunter-gatherers of 2 million years ago or alternatively, that we are simply observing the by-products of the relevant mechanisms. To further complicate this picture, many adaptations are not so much elegant design solutions to adaptive demands but, rather, compromises between conflicting environmental demands.

At the same time, EP is a new approach to human behavior and psychopathology that remains highly speculative and in need of considerable empirical support. Consequently, to demonstrate the promise that we consider it offers, we briefly outline how an evolutionary perspective has recently begun to shed new light on two specific disorders, autism and depression. There are numerous other examples that we could also have included had space allowed, such as agoraphobia and panic disorder (Nesse, 1997), anorexia nervosa (McGuire \& Troisi, 1998), dysthymic disorder (McGuire \& Troisi, 1998), homicide (Daly \& Wilson, 1998), phobias (McGuire \& Troisi, 1998), personality disorders (Millon \& Davis, 1996), psychopathy (Mealey, 1995), and schizophrenia (Crow, 1995). Evolutionary accounts of anxiety probably represent the best known and most influential of attempts to apply Darwinian theory to human psychological dysfunction. As examples, Marks (1969, p. 16) observed that "fear is an innate emotional response in higher animals which has obvious survival value," and, more recently, Bruce and Sanderson (1998, p. 11) observed that "most phobias do seem to develop in response to threats of evolutionary significance." 
As discussed earlier, the popularity of animal models of psychopathology and, in particular, Seligman's (1971) article "Phobias and Preparedness" had lent credibility to such evolutionary explanations. Even 30 years after that influential article, there is still a vigorous ongoing argument over the degree to which certain fears (such as fear of heights, snakes, and spiders) are more or less easily acquired than other fears that have less obvious biological or evolutionary salience (e.g., Davey, 1995; McNally, 1987; Menzies \& Parker, 2001; Poulton, Waldie, Menzies, Craske, \& Silva, 2001). However, the putative relevance of evolutionary theory for understanding anxiety is probably fairly well known, if not always accepted, by most psychologists who study psychopathology. Consequently, we have chosen two disorders, autism and depression, that have only recently been subject to evolutionary theorizing in an attempt to demonstrate the potential scope, novelty, and breadth of an evolutionary perspective.

\section{Autism and Evolution}

Autism is a developmental disorder that arises in early childhood (within the first 30 months) and is characterized by three major classes of symptoms: social impairment, communication impairment, and a restricted repertoire of activities and interests (American Psychiatric Association, 1994; Mesibov, Adams, \& Klinger, 1997). There are several different diagnostic criteria within each of these three areas of functioning, and a child must meet at least two of the criteria from the social category and at least one criterion from both of the two remaining categories. The disorder may be accompanied by mental retardation or occur in the context of normal intelligence.

Autism was first described and named by Kanner (1943, as cited in Mesibov et al., 1997), who called it "early infantile autism" and drew a distinction between autism and childhood schizophrenia. Whereas early theories posited psychoanalytic explanations of its etiology (e.g., Bettelheim, 1967), contemporary accounts assume a physiological basis expressed in neurocognitive difficulties (e.g., Frith, 1989). However, the precise nature of that physiological basis remains somewhat elusive (Mesibov et al., 1997). Although relatively rare, this disorder has typically attracted a considerable amount of attention from researchers in psychopathology.

Among the striking symptoms of the disorder that may in part account for the intense interest it has attracted are the interpersonal deficits that characterize autism. For example, the Diagnostic and Statistical Manual of Mental Disorders (fourth edition; DSM-IV; American Psychiatric Association, 1994) includes the following among the diagnostic criteria for social impairment: impaired use of nonverbal behavior; lack of peer relationships; failure to spontaneously share enjoyment, interests, and achievements with others; and lack of reciprocity. Young children with autism may seem indifferent to the company of other people, including their parents. They may not show interest in playing with other children or seem able to form friendships, and they frequently appear uncommunicative, withdrawn, and lost in their own world. The autistic person typically has difficulty mastering elementary social skills and finds the behavior of other people confusing and difficult to understand (Baron-Cohen \& Bolton, 1993). In attempting to understand autism and, in particular, explain the interpersonal aloofness and social inadequacies that seem so characteristic of this disorder, Baron-Cohen (1995) has drawn on a developmental theory known as the theory of mind.

Interest in the ability of humans (and other primates) to form mental representations of another individual's thought processes has exploded since Premack and Woodruff (1978) posed the question "Does the chimpanzee have a theory of mind?" Since then the concept has generated intense interest in developmental psychology (e.g., Butterworth, Harris, Leslie, \& Wellman, 1991), developmental psychopathology (Baron-Cohen, 1995), and cognitive anthropology (Lillard, 1998). Baron-Cohen has suggested that the ability to form accurate mental representations of what another person is thinking has special relevance for understanding autism. This ability is often called "mind reading."

Mind reading refers to the ability to make inferences about other people's intentions, wishes, emotions, desires, beliefs, and attitudes based on observation of their external behavior in any particular context. Baron-Cohen argued that humans are naturally proficient at mind reading in the same way that other species are 
proficient at camouflaging themselves or seeing in the dark. The mind reading ability of Homo sapiens has evolved over millions of years, presumably because good mind readers reproduced more successfully. Baron-Cohen noted the survival value of mind reading in the following passage: "It is evident, I think, that if another organism's next action is going to be to attack you, or to share its food with you, or to mate with you, you do well to anticipate this quickly, since any of these actions could indeed 'affect reproduction, however distally" " (1995, p. 12).

Baron-Cohen argued that one important factor in the large increase in brain size during the Pleistocene epoch (roughly the past 2 million years) was the need for greater social intelligence. He commented that, for primates living in social groups, the challenge was "to understand, predict and manipulate the behavior of others in the group" (Baron-Cohen, 1995, p. 15). What, then, is the relevance of all this for children and adults with autism? In a nutshell, Baron-Cohen hypothesized that, in autism, the "mind reading module" is dysfunctional.

Baron-Cohen, Leslie, and Frith (1985), in their article "Does the Autistic Child Have a 'Theory of Mind'?" argued that three of the classic symptoms of autism-social skills deficits, poor communication skills, and an inability to engage in pretend play-could all be explained by a failure to develop mind reading abilities. The child with autism, it is hypothesized, can interact with other people only on the basis of observed behaviors. Thus, the abilities to take another person's perspective, to develop empathy, and to comprehend what is implied in an utterance rather than interpreting the spoken message entirely literally will be lacking in autistic individuals.

Indeed, Baron-Cohen, along with Uta Frith and others, has collected an impressive body of data from experiments with autistic participants that essentially supports this theory (BaronCohen, 1997; Baron-Cohen, O'Riordan, Stone, Jones, \& Plaisted, 1999; Frith, 1989). Moreover, the heuristic value of this theory has also begun to be demonstrated, both in terms of developing new interventions for autism (Hadwin, Baron-Cohen, Howlin, \& Hill, 1997; Reinecke, Newman, Kurtz, Ryan, \& Hemmes, 1997), and its possible relevance for generating theory regarding other disorders (Drury, Robin- son, \& Birchwood, 1998; Langdon \& Coltheart, 1999).

In summary, Baron-Cohen has proposed that natural selection has resulted in humans having a built-in "neurocognitive mechanism" that helps them understand the behavior of others: the so-called mind reading module. Moreover, he has suggested that this mechanism is impaired or fails to develop normally in autism, producing several of its hallmark symptoms. There is a substantial body of data accumulating to support this hypothesis. Interested readers would do well to consult either Baron-Cohen (1997) or Frith (1989) as a starting point in familiarizing themselves with the research in this area. For our purposes, it is sufficient to note that an evolutionary approach has helped to construct an influential new theory for understanding autism but also that data from the field of developmental psychopathology are simultaneously informing EP with regard to a domainspecific region of cognition that constitutes a part of our cognitive architecture.

\section{An Evolutionary Perspective on Depression}

Depression is a mental disorder characterized by symptoms that can include sadness, pessimism, despair, guilt, anhedonia, fatigue, sleep disorder, feelings of extreme worthlessness, concentration difficulties, and sometimes suicide. It is an extremely common illness. The lifetime prevalence rates reported in surveys of community samples typically vary from $5 \%$ to $12 \%$ for males and from $10 \%-25 \%$ for females (American Psychiatric Association, 1994). As a result of the high prevalence of depression and the fact that it frequently involves somatic symptoms (i.e., reduced appetite, reduced libido, and sleep disturbance), biological explanations have been influential on models of etiology and modes of therapy (Shelton, Hollon, Purdon, \& Loosen, 1991). Perhaps as a consequence, evolutionary explanations have been relatively popular for explaining at least some aspects of depression (e.g., Beck, 1976; Gilbert, 1992; McGuire \& Troisi, 1998; Price, 1967).

In fact, within the field of evolutionary psychopathology, there are a number of different accounts of depression (interested readers are referred to McGuire \& Troisi, 1998, for an overview). We consider just one model of 
depression based on evolutionary concepts, namely the social competition hypothesis advanced by Price, Sloman, Gardner, Gilbert, and Rohde (1994). Furthermore, we address only unipolar depression (for an evolutionary explanation of bipolar disorder, see D. R. Wilson, 1998).

Price et al. (1994) offered an evolutionary account of depression in which depression was considered to have evolved in relation to social competition as an "unconscious, involuntary losing strategy, enabling the individual to accept defeat in ritual agonistic encounters and to accommodate to what would otherwise be unacceptably low social rank" (p. 241). Such a model is based on the idea that depression serves an adaptive function and that the function of depression is in relation to social competition.

Price et al. (1994) hypothesized that depression evolved as a "mechanism for yielding in competitive situations" (p. 242). It is considered an involuntary mechanism that inhibits aggression toward more dominant individuals and signals to those competitors that the individual is not a threat. It is also posited to produce a state of mind conducive to giving up and accepting the situation, which Price et al. labeled "voluntary yielding." Price et al. suggested that this mechanism of depression evolved out of "ritual agonistic behavior," which they pointed out is the primary form of social competition underlying sexual selection in most vertebrates. They argued that agonistic behavior is closely related to a self-concept known as resource-holding potential that equates with the fighting capacity of an individual as perceived by that individual and by others. Price et al. even went as far as to hypothesize that self-esteem evolved out of resource-holding potential.

In some ways, this all seems rather removed from our contemporary social context in which physical combat is rarely used in settling disputes. However, the theory becomes less esoteric when we note Price et al.'s (1994) comment that "ritual agonistic behavior is not the main form of human social competition" any longer but rather that "competition by attraction has largely replaced competition by intimidation" (pp. 245-246). Thus, we can no longer gain social status simply by physically dominating our fellows (except perhaps in the sporting arena and certain criminal subcultures); instead, we must rely on our interpersonal skills, personality, physical attractiveness, and so forth. Therefore, it follows that depression may represent a failure to achieve or maintain status and control in the interpersonal realm and a subsequent withdrawal both physically and psychologically.

It is also worth noting that Price et al. (1994) stated that the simplest hierarchy is the twoperson relationship. They suggested that in many dyads, the depressed person occupies a permanently "one-down" position in the relationship, which serves to avoid a psychological "arms race." The depressed person's status is chronically diminished and his or her partner's magnified, and this is associated with cognitive distortions in the depressed partner. Such a scenario may already be familiar to many clinicians reading this article, but the evolutionary account is, we believe, quite novel. Thus, although the evolutionary model of depression brings a new theoretical perspective to the clinic, the issues of status, self-esteem, dominance, and control within relationships, which the model predicts will be salient in depression, are familiar to most clinicians working with people with depression.

Another interesting corollary of the social competition hypothesis is the suggestion from Price et al. (1994) that "depression functions to inhibit aggression" (p. 249). This hypothesis is somewhat reminiscent of the traditional psychoanalytic notion that depression involves anger turned inward against the self, a hypothesis that has not been empirically supported, and some evidence even exists suggesting that depressed people may express more anger than controls (Davison \& Neale, 1998). The social competition hypothesis suggests a more complex picture. In particular, it posits that expressing hostility upward in a hierarchy has very different meanings and consequences from expressing it downward. Price et al. stated that "only hostility to equal- and higher-ranking people is inhibited, whereas hostility expressed to lower ranking people is often increased" (1994, p. 249). Consequently, we expect to see more complicated formulations than simply "Repressed hostility leads to depression." For example, a man who finds it difficult to be assertive at work with superiors and senior colleagues may then express his hostility to his wife or children. 
There are admittedly some problems involved with this model. An obvious one is how to explain the frequent observation that depression is more common among women than men, given that agonistic behavior is generally considered more common among males. Price et al. (1994) suggested, in relation to this issue, that agonistic behavior may be more conspicuous, rather than more frequent, among males. They also cited evidence that the gender difference decreases as equality between the sexes increases, an observation consistent with a social competition hypothesis. In summary, Price's social competition theory of depression is consistent with a wide range of data from both epidemiology and animal models of depression, and Price has suggested a number of implications for both research and treatment (Price et al., 1994). At the same time, the theory remains largely speculative and, to date, has not been directly tested experimentally with human participants.

\section{Implications for $\mathrm{CP}$ of an Evolutionary Perspective}

Taking an evolutionary perspective on $\mathrm{CP}$ has important implications for developing etiological theories, for assessment, for treatment, and for ethics. We briefly address each of these domains.

\section{Implications for Theory and Etiology of Mental Disorders}

Perhaps the major contribution of adopting an evolutionary perspective on mental disorder will be in relation to developing robust and meaningful etiological models. Mental disorders represent a vast and bewildering array of signs and symptoms that seem to defy any simple approach to their taxonomy. For example, schizophrenia is a common and disabling disorder, occurring in about $1 \%$ of the population throughout the world, and yet there is no one symptom that everyone must display who merits the diagnosis. Heinrichs (1993) has called this the "heterogeneity problem." One outcome of this confusion has been a proliferation of new diagnostic labels. In fact, a major constraint on the development of the DSM-IV was concern regarding the proliferation of new diagnostic categories with each revision (see Clarke, Watson, \& Reynolds, 1995).

To complicate things further, there is no generally agreed on etiological perspective to explain this ever expanding catalogue of mental disorders. To the contrary, individual clinicians subscribe to psychodynamic, cognitive-behavioral, biological, or family systems models of dysfunction. Theoretical pluralism is the order of the day. Reflecting this theoretical agnosticism in the marketplace, developers of recent versions of the DSM have striven for operational definitions of mental disorders that mostly ignore the issue of etiology (save for the indisputably "organic" disorders). This has even produced a somewhat Kafkaesque situation whereby each new version of the DSM is followed by dozens of research studies on the technical merits (reliability and validity) of the new diagnostic categories. Such research may produce publications, but it does little to explain the phenomena of concern, nor does it often generate meaningful theory. At its worst, this type of research makes the diagnostic manual itself the focus, rather than those naturally occurring phenomena (i.e., mental disorders) on which it is supposed to facilitate research.

An evolutionary perspective may help temper such excesses by providing a broad and unifying theory that integrates the study of psychopathology and connects it with other biological and social sciences. It allows for the integration of data from a variety of etiological models (e.g., genetic, biochemical, developmental, and cognitive) through its emphasis on the role of ultimate causes and their interaction with proximate causes. Much of the debate surrounding competing explanations of mental disorder is concerned with different explanations of the proximate causes of an illness. For example, in explaining a case of depression, we can look to the person's developmental history for vulnerability factors, we can examine the person's current cognitions for depressogenic schemas, or we might attribute the person's depression to serotonin imbalance or depletion in the central nervous system. Furthermore, all three approaches have their value in explaining certain aspects of the disorder. However, only ultimate (i.e., evolutionary) causes explain why humans become depressed in the first place.

Moreover, ultimate explanations are important because they constrain the form of proxi- 
mate explanations and, in a sense, dictate what is possible. For example, if the ultimate cause of depression is related to an individual's lack of status, relevant proximal causes might plausibly involve appraisal mechanisms or beliefs concerning the individual's lack of ability or value. Appeals to mechanisms associated with unrelated causes, such as anger turned inward or a loss of existential meaning, would only be reasonable (in this view) if they were by-products of, or causally activated by, the more central proximal causes. In this case, these are selfappraisal mechanisms and core beliefs concerning self-worth and status.

Unless a theory of depression can invoke ultimate as well as proximate causes and attempt to detail their interaction, it will at best only ever be a partial explanation of the phenomenon. Thus, an evolutionary perspective on mental disorder offers greater theoretical unity and integration and a more comprehensive account of the phenomenon of interest. It also provides a framework for more rigorous theory development. Explanations for a disorder not only must make logical sense within themselves (i.e., show internal coherence) but must be consistent with the broader facts of hominid evolution (i.e., show external coherence $^{3}$ ).

Another important insight from EP concerns the possibility that mental disorders may be the product of mechanisms functioning normally but in currently nonadaptive circumstances (Gilbert, 1998b). Buss (1999) suggested that there are at least four ways this could occur. First, there may be a discrepancy between modern and early ancestral environments that makes evolved mechanisms currently maladaptive. For example, because of access to lethal weapons, male jealousy may result in more serious crimes than in the past, despite jealousy having the evolved function of mate guarding. Second, problems may emerge because normally functioning mechanisms may occasionally result in mistakes. For example, males' tendency to infer sexual interest in females when there is none may result in sexual aggression in certain contexts.

Third, subjective distress may be caused by the normal operation of psychological mechanisms resulting in a diagnosis of a mental disorder. For example, as described earlier, depres- sion may be quite adaptive despite its adverse psychological effects on individuals. Finally, socially undesirable behavior may be caused by the normal operation of psychological mechanisms and result in a diagnosis of a mental disorder. For example, child neglect and abuse may simply reflect evolutionary sound decisions to reduce investment in nonrelatives rather than individual psychopathology. The resulting outcome may be morally wrong and socially undesirable, but it is not necessarily an example of psychopathology.

Classification is essential to our understanding of psychopathology and to the construction of good theory (Millon, 1991). A reliable and valid classificatory system also is essential for designing and evaluating treatment and in predicting future risk. We briefly describe two notable examples of an evolutionary approach to classification and etiology that already exist. Wakefield (1992), as mentioned previously, has proposed a solution to the enduring issue of how best to define mental disorder, in terms of "harmful dysfunction." This concept attempts to combine both the social values and the scientific values involved in classifying behavior as "abnormal." Its significance resides in an explicit acknowledgment that psychiatric diagnosis attempts a scientific classification of phenomena that are sometimes only deviant or abnormal in terms of social values. For example, Wakefield noted that, as a result of changing social mores, homosexuality is no longer included in the $D S M$.

Wakefield's solution is that any mental disorder must demonstrate two distinct properties. First, the disorder must be considered harmful to the individual or other people in terms of current social values. Second (and most relevant to this discussion), a dysfunction must be evident. Wakefield (1992) defined dysfunction as a "scientific term referring to the failure of a mental mechanism to perform a natural function for which it was designed by evolution" ( $p$. 373). Consequently, his definition combines both value and scientific components but is ex-

\footnotetext{
${ }^{3}$ As an example, Thornhill and Palmer (2000) have argued that Freud's Oedipal theory would have quickly died if required to meet this criterion. Put bluntly, any species in which all males experienced a desire to mate with their mothers (conscious or unconscious) would have rapidly bred itself into extinction.
} 
plicit in trying to disentangle them. The notion of dysfunction in evolutionary terms is not without its problems. For a detailed examination of some of these issues, we refer readers to a recent special issue of the Journal of Abnormal Psychology (e.g., Wakefield, 1999). For our purposes, it is sufficient to note that one of the most influential definitions of mental disorder to arise in recent years takes an evolutionary perspective.

Another approach to classification and etiology from an evolutionary perspective has been advanced by McGuire and Troisi (1998). They have suggested grouping disorders that have "similar functional consequences within the same behavior system" (p. 151). Hence, disorders that relate to the reproductive behavior system are grouped together, as are disorders that relate to the survival behavior system, the kin investment behavior system, and so on. Therefore, because anorexia nervosa, dysthymia, sexual and gender identity disorder, hypoactive sexual desire disorder, sexual abuse of a child, and histrionic personality disorder all decrease the frequency of normal sexual functioning, they are clustered together within the reproductive behavior system category.

According to McGuire and Troisi, the principal advantage of such an approach is that groupings based on the functions of a behavior system, or functional failures, are explicitly tied to causal hypotheses concerning etiology. They noted that their provisional classification system is informative in two important ways. First, the disorders grouped by behavioral system all share similar features. For example, the disorders grouped under the survival behavior system are all characterized by strong feelings of personal danger and exaggerated responses to fearful situations. Second, the disorders within each group are likely to share similar ultimate but not proximate causes. McGuire and Troisi noted that their model is most consistent with complex, multiple-variable explanations of mental disorder. In summary, we have described recent examples of an evolutionary approach to the definition and classification of mental disorder. Both are characterized by a strong theoretical framework that stands in contrast to the theoretical agnosticism of the $D S M-I V$.

\section{Implications for Assessment}

An evolutionary perspective on $\mathrm{CP}$ will have many implications for the assessment of clients with clinical disorders and problems in living. Here we focus on just one important implication for assessment, the nature of mind that clinical psychologists possess when working with their clients. Although argument continues about the extent of modularity or even the existence of specific modules in the mind, there is general agreement among evolutionary psychologists that the human mind has evolved not as a general purpose (i.e., undifferentiated) computer but, rather, as a complex set of specialized computing devices that somehow act in a more or less coordinated fashion.

This idea has two important implications. First, our minds evolved to cope with an environment totally different from contemporary Western societies. Second, our minds comprise a number of specialized information-processing mechanisms that are content specific. A number of examples of such mechanisms, suggested by Tooby and Cosmides, include mechanisms for mate selection, language acquisition, family relations and cooperation, and a theory of mind (Tooby \& Cosmides, 1992, pp. 24, 92). In this regard, EP is radically different from the cognitive psychology that has dominated academic psychology since the 1960s. EP insists that to study the mind, one must begin by considering the environmental challenges that characterized the environment of evolutionary adaptation and produced adaptations. One will not achieve rapid insights into human cognition by exhaustive examination of reaction times on tasks for which the brain was never designed to be proficient. Yet, modern cognitive psychology has, to a degree, become focused on experimental procedures or paradigms rather than the natural phenomena they are supposed to explain.

In contrast, EP offers a powerful new method for studying human cognition and emotion, demanding that before we begin designing experiments or surveys, we are explicit and clear about the nature of the mind we are studying. We should be able to answer (or at least have tried to answer) four questions raised by Cosmides and Tooby (2000):

1. Where in the brain are the relevant circuits and how, physically, do they work? 
2. What kind of information is being processed by these circuits?

3. What information-processing programs do these circuits embody?

4. What were these circuits designed to accomplish (in a hunter-gatherer context)?

Cosmides and Tooby argued that an evolutionary approach can be applied to any topic, including human sexual behavior, cooperation, rational thinking and decision making, aggression, schizophrenia, and so on.

Thus, it is argued that an EP perspective alters the very nature of the model of mind we employ as clinicians working with individual clients or when conducting research on clinical disorders. In assessment terms, we may wish to consider the kinds of evolved modules or mechanisms we are dealing with and how proximate variables invoke these mechanisms. On a broader theoretical level, EP offers a radically new approach for the study of cognition that may have direct relevance for $\mathrm{CP}$, especially given its focus on such domains as mate selection, sexual jealousy, social cooperation and communication, and "mind reading" abilities. By contrast, traditional approaches to the study of cognition have often seemed absorbed by methodological tasks of little ecological validity or relevance to clinical issues. Consequently, EP may provide a theoretical and empirical foundation for studying clinical problems that is based directly on the mechanisms involved and is more directly relevant to $\mathrm{CP}$ than much of current cognitive psychology.

\section{Implications for Treatment}

Perhaps the most fundamental influence on treatment will spring from adopting a concept of mind radically different from that advanced under the SSSM. Instead of a general computing device molded largely by culture, we now envisage a highly specialized biological computer that has evolved to perform a number of specific functions. Thus, in designing therapeutic interventions we may need to be more specific about which cognitive modules they are designed to influence or interact with. One example of this level of specificity already exists in some recent work with autistic children.

As described earlier, a considerable body of evidence has accumulated to suggest that autistic children are particularly poor at understand- ing the workings of other people's minds (socalled "mind reading" ability). Moreover, Baron-Cohen has proposed that this might reflect a failure in a cognitive module specialized for understanding the intentions, beliefs, desires, and motivations of other people. Such a specialized ability would have had obvious survival value for humans who existed for millions of years in small social groups as hunter-gatherers. Some recent work has attempted to train these abilities in people with autism. The results to date are somewhat mixed. For example, Reinecke et al. (1997) showed that (in the context of a game) young people with autism could learn "deception skills." Hadwin et al. (1997) attempted to teach children with autism to assess other people's mental states. Whereas some learning took place, it was not reflected in improved scores on communication measures, although such research is still in its infancy. What is clear from this work, nonetheless, is that an understanding of the disorder in terms of the specific cognitive mechanisms involved has direct implications for developing new treatment approaches.

Another implication for treatment is that we may also have to adopt a different, and more complex, model of mental disorders. Current models of pathology in CP frequently conceptualize mental disorders either as illnesses or as learned behaviors. For example, panic disorder can be regarded as a mental illness. It has specific signs and symptoms, there is some evidence for genetic correlates, and it can be treated with drugs. Alternatively, it can be viewed as primarily a behavioral problem in which vulnerability factors, combined with a particular learning history, result in the individual learning to respond to certain environmental cues with panic. Both of these approaches to anxiety begin with the assumption that high levels of anxiety are abnormal, unhealthy, and pathological.

However, Nesse and Williams (1997) have argued that from an evolutionary perspective, both approaches may be in error in regarding strong emotions as strictly pathological. For example, in ancestral environments anxiety functioned as an alarm system that alerted individuals to possible threats and forced them to take immediate action. In other words, anxiety had (and in many cases still has) survival value. If one is sleeping in the wild and woken at night 
by the sound of a snapping twig, there is survival value in taking immediate action (either fleeing or perhaps waking one's kin and arming oneself). As Gilbert (1998b) has argued, in such situations there is little cost for false alarms. However, to remain calm and demand further evidence of a real threat before responding could well result in death. Thus, in many situations we react with emotions that are both immediate and powerful, because those emotions previously had adaptive survival value.

Nesse and Williams (1997) asserted that many aspects of mental disorders, such as anxiety, are actually defensive systems in the same way that a cough is a defense against accumulated phlegm in the lungs. This is not to suggest that all anxiety is useful or that we understand anxiety as well as we understand the common cough. It does suggest, however, that anxiety is normal, that it has been adaptive in past environments, and that we cannot simply assume it is the by-product of some aberration in brain chemistry. No doubt the same arguments could apply to other disorders as well. In fact, searching for abnormalities in the brains of anxiety sufferers may be a complete red herring. Nesse and Williams cautioned that this could be analogous to studying the purpose and function of coughing by investigating the respiratory systems of people with severe coughs. That is, a cough is a defensive reaction to a multitude of infectious and immune disorders, not a disorder in its own right. Again, an evolutionary perspective implies a radical shift in our thinking concerning the nature of mental disorders. Many of the "maladaptive behaviors" that fill the pages of undergraduate texts on abnormal psychology may actually be behavioral systems that had survival value and have been selected by evolution over millions of years.

Gilbert (1998b) made a similar argument in relation to cognitive distortions, noting that human cognition evolved to react rapidly to threats, both social and nonsocial in nature. Thus, much of human cognition is not fundamentally rational in nature, and, as EP would suggest, it is also domain specific and fast. Gilbert argued that in depression, for example, it is not so much a question of learning to think in an irrational or depressogenic style; rather, the information-processing algorithm concerned has been activated. He suggested that this might explain why people with no history of depres- sion or vulnerability factors can nonetheless become depressed and display the full spectrum of cognitive distortions in response to traumatic head injury or certain medications. One implication of this notion, according to Gilbert (1998b, p. 459), is that "cognitions are far more socially contextualized than currently considered." He seemed to be saying that we can all become depressed because of our evolutionary past but that we need to look at the environments of those who do become depressed to see what activates this potential, rather than focusing overly on the thinking of the depressed person.

A further implication for treatment mentioned by Gilbert is that some therapists may want to share evolutionary explanations with their clients or patients. He suggested that cognitive therapy can be explained partly as learning to switch off or attenuate normal defensive mechanisms. This means there is less need to hold up some ideal standard of rational thinking as the norm and, in so doing, emphasize the patient's own thoughts as irrational, distorted, and inadequate. Rather, such distorted cognitions can be normalized so as to reduce the client's existing feelings of failure, inadequacy, and unworthiness. At the same time, it can be clearly stated to the client that a tendency toward such thinking, although normal in its origins, is self-defeating in the current environment because it is too intense, too prolonged, and too pervasive.

\section{Ethical Implications}

Evolutionary perspectives assume that the most appropriate framework for approaching the study of human beings is naturalistic in nature and should stress the common features shared by all living things. An important issue concerns human goods or values and whether they are rooted in the nature of human beings. Arnhart (1998) argued persuasively that "the good is the desirable ... human ethics is natural insofar as it satisfies natural human desires" (p. 29). He added that "I call these desires natural because they are so deeply rooted in human nature that they will manifest themselves in some manner across history in every human society" (p. 29). According to Arnhart, there are at least 20 different kinds of natural desires or goods, including religious and intellectual un- 
derstanding, sexual mating, familial bonding, parental care, friendship, beauty, wealth, social ranking, and practical reasoning. Because these desires represent basic goods, political and social systems can be evaluated in terms of how well they promote these goods relative to other possible arrangements.

The etiological and clinical theories used by psychologists in their everyday practice assume a particular view of human nature, for example, whether or not our minds share a common architecture. Therapy goals are based on judgments concerning the best possible outcomes for clients: essentially, a vision of human flourishing and well-being. Accepting a naturalistic model of human nature means that clinicians need to carefully evaluate their clinical theories to ensure they are not seeking outcomes that frustrate natural goods. For example, overlooking the innate need to establish a sense of meaning and value in our lives will diminish the chances of an effective therapy outcome. Or attempting to foster nonviolent conflict resolution skills in males while ignoring their proclivity to engage in competitive behavior may prove fruitless. Finally, striving to help couples develop a better understanding of each other should arguably take into account evolved gender differences. This process involves ethical judgments because of the relationship between natural goods and ideal therapy outcomes. The assessment and intervention phases of clinical reasoning are shot through with normative commitments and judgments.

A final ethical issue concerns the need for psychologists to consider the existing political and social backdrop when formulating theories or innovative treatment techniques. We are not suggesting that psychologists should strive to be politically correct and subvert the pursuit of truth merely to avoid offending some members of the community. However, it is becoming clear that different therapeutic traditions have distinct models of human nature and therefore contrasting visions of what constitutes a "good" outcome for a client (Arnhart, 1998). The values attached to such models may have quite profound social and cultural implications and legitimately attract criticism from nonpsychologists. It is important to consider these issues when promoting theories or practices that could cause offense to others and run the risk of being misinterpreted.
The public response to an influential evolutionary theory of rape developed by Thornhill and Palmer (2000) is an excellent example of this issue. In a nutshell, this perspective attempts to explain rape by appealing to evolutionary theory and the construct of natural selection. According to the theory, rape is either directly or indirectly associated with inherited traits that, in the distant past (about 2 million years ago), increased our ancestors' reproductive success. This theory has attracted a great deal of attention, typically extremely negative in nature, in the popular press and in the wider community. The major concern expressed by individuals is that evolutionary approaches to the explanation of sexual aggression are rigidly deterministic, are narrow in focus, and appear to absolve rapists of any responsibility for their abusive behavior.

In our opinion, many of these criticisms are misguided and rest on misunderstandings of EP in general and evolutionary theories of rape in particular. However, we believe that the manner in which Thornhill and Palmer constructed their argument and the disparaging way they referred to other theories of rape helped to inflame their critics. Thus, psychological theories are always developed within a specific social context, and it is important that we are sensitive to this context when developing ideas likely to arouse intense public interest and scrutiny.

\section{Summary and Conclusion}

In this article, we have argued that EP is a major development in contemporary psychology that has been largely ignored by $\mathrm{CP}$. The history of $\mathrm{CP}$ shows that Darwin's ideas were quite influential in the early history of the field, especially the mental testing movement but both the early Freudian and behaviorist theories as well. However, by the 1920s and 1930s this influence had begun to disappear in $\mathrm{CP}$, and it did not reemerge until the early 1970s, when animal models of psychopathology became increasingly popular.

Similar trends can be observed in psychiatry and the social sciences. The value of incorporating evolutionary concepts into the understanding of mental disorders was illustrated with reference to the emerging field known as evolutionary psychopathology. The merits of evolutionary explanations for mental disorders 
were illustrated with reference to autism and depression. Evolutionary psychopathology is a multidisciplinary field in which several of the major contributors have been psychologists; however, its impact on the field of $\mathrm{CP}$ remains to be seen. We conclude that $\mathrm{CP}$ can no longer afford to ignore the important theoretical insights offered by EP and evolutionary psychopathology. It is time for a closer dialogue between these two scientific disciplines, and we hope we will soon see the emergence of an evolutionary $\mathrm{CP}$.

\section{References}

American Psychiatric Association. (1994). Diagnostic and statistical manual of mental disorders (4th ed.). Washington, DC: Author.

Arnhart, L. (1998). Darwinian natural right: The biological ethics of human nature. Albany: State University of New York Press.

Barkow, J., Cosmides, L., \& Tooby, J. (1992). The adapted mind: Evolutionary psychology and the generation of culture. New York: Oxford University Press.

Baron-Cohen, S. (1995). Mindblindness: An essay on autism and theory of mind. London: MIT Press.

Baron-Cohen, S. (Ed.). (1997). The maladapted mind: Classic readings in evolutionary psychopathology. Hove, England: Psychology Press.

Baron-Cohen, S., \& Bolton, P. (1993). Autism: The facts. Oxford, England: Oxford University Press.

Baron-Cohen, S., Leslie, A. M., \& Frith, U. (1985). Does the autistic child have a "theory of mind"? Cognition, 21, 37-46.

Baron-Cohen, S., O'Riordan, M., Stone, V., Jones, R., \& Plaisted, K. (1999). Recognition of faux pas by normally developing children with Asperger's syndrome or high-functioning autism. Journal of Autism \& Developmental Disorders, 29, 407-418.

Beck, A. T. (1976). Cognitive therapy and emotional disorders. New York: Meridian.

Bettelheim, B. (1967). The empty fortress. New York: Free Press.

Bowlby, J. (1969). Attachment and loss (Vol. 1). London: Hogarth Press.

Brems, C., Thevenin, D. M., \& Routh, D. K. (1991). The history of clinical psychology. In C. E. Walker (Ed.), Clinical psychology: Historical and research foundations (pp. 3-35). New York: Plenum.

Bruce, T. J., \& Sanderson, W. C. (1998). Specific phobias: Clinical applications of evidence-based psychotherapy. Northvale, NJ: Jason Aronson.

Buss, D. M. (1999). Evolutionary psychology: The new science of the mind. Boston: Allyn \& Bacon.
Buss, D. M., \& Schmitt, D. P. (1993). Sexual strategies theory: An evolutionary perspective on human mating. Psychological Review, 100, 204-232.

Butler, S. F., \& Strupp, H. H. (1991). Psychodynamic psychotherapy. In M. Hersen, A. E. Kazdin, \& A. S. Bellack (Eds.), The clinical psychology handbook (pp. 519-533). New York: Pergamon Press.

Butterworth, G., Harris, P. L., Leslie, A. M., \& Wellman, H. M. (Eds.). (1991). Perspectives on the child's theory of mind. New York: Oxford University Press.

Clarke, L. A., Watson, D., \& Reynolds, S. (1995). Diagnosis and classification of psychopathology: Challenges to the current system and future directions. Annual Review of Psychology, 46, 121-153.

Cosmides, L., \& Tooby, J. (1989). Evolutionary psychology and the generation of culture, Part II. Case study: A computational theory of social exchange. Ethology and Sociobiology, 10, 51-97.

Cosmides, L., \& Tooby, J. (2000). Evolutionary psychology: A primer. Retrieved January 3, 2000, from http://cogweb.english.ucsb.edu/EP/EP-primer. html

Crow, T. J. (1995). A Darwinian approach to the origins of psychosis. British Journal of Psychiatry, $167,12-25$.

Daly, M., \& Wilson, M. (1998). Evolutionary social psychology and family homicide. Science, 242, 519-524.

Darwin, C. (1998). The origin of species. Hertfordshire, England: Wordsworth. (Original work published 1859)

Davey, G. C. (1995). Preparedness and phobias: Specific evolved associations or a generalized expectancy bias? Behavioral and Brain Sciences, 18, 289-325.

Davison, G. C., \& Neale, J. M. (1998). Abnormal psychology (7th ed.). New York: Wiley.

Deacon, T. (1997). The symbolic species: The coevolution of language and the human brain. London: Penguin Books.

Drury, V. M., Robinson, E. J., \& Birchwood, M. (1998). 'Theory of mind' skills during an acute episode of psychosis and following recovery. Psychological Medicine, 28, 1101-1112.

Durrant, R. (1998). A natural history of the mind: The role of evolutionary explanations in psychology. Unpublished doctoral dissertation: University of Canterbury, New Zealand.

Eysenck, H. J., \& Rachman, S. (1965). The causes and cures of neurosis. San Diego, CA: Knapp.

Fodor, J. A. (1983). The modularity of mind. Cambridge, MA: MIT Press.

Frith, U. (1989). Autism: Explaining the enigma. London: Blackwell.

Gilbert, P. (1992). Depression: The evolution of powerlessness. New York: Guilford Press. 
Gilbert, P. (1998a). Evolutionary psychopathology: Why isn't the mind designed better than it is? British Journal of Medical Psychology, 71, 353373.

Gilbert, P. (1998b). The evolved basis and adaptive functions of cognitive distortions. British Journal of Medical Psychology, 71, 447-463.

Hadwin, J., Baron-Cohen, S., Howlin, P., \& Hill, K. (1997). Does teaching theory of mind have an effect on the ability to develop conversation in children with autism? Journal of Autism and Developmental Disorders, 27, 519-537.

Heinrichs, R. W. (1993). Schizophrenia and the brain: Conditions for a neuropsychology of madness. American Psychologist, 48, 221-233.

Hergenhahn, B. R. (1992). An introduction to the history of psychology. Belmont, CA: Wadsworth.

Hergenhahn, B. R., \& Olson, M. H. (1993). An introduction to theories of learning. Englewood Cliffs, NJ: Prentice Hall.

Hilgard, E. R. (1987). Psychology in America: A historical survey. San Diego, CA: Harcourt Brace Jovanovich.

Hirschfeld, L. A., \& Gelman, S. A. (Eds.). (1994). Mapping the mind: Domain specificity in cognition and culture. Cambridge, England: Cambridge University Press.

Karmiloff-Smith, A. (1992). Beyond modularity: A developmental perspective on cognitive science. Cambridge, MA: MIT Press.

Karmiloff-Smith, A. (2000). Why babies' brains are not Swiss army knives. In H. Rose \& S. Rose (Eds.), Alas poor Darwin: Arguments against evolutionary psychology (pp. 144-156). London: Johnathon Cape.

Langdon, R., \& Coltheart, M. (1999). Mentalising, schizotypy, and schizophrenia. Cognition, 71, 4371.

LeDoux, J. (1998). The emotional brain. London, UK: Phoenix.

Lillard, A. (1998). Ethnopsychologies: Cultural variations in theories of mind. Psychological Bulletin, 123, 3-32.

Malamuth, N. M., \& Heilman, M. F. (1998). In C. B. Crawford \& D. L. Krebs (Eds.), Handbook of evolutionary psychology: Ideas, issues and applications (pp. 515-542). Mahwah, NJ: Erlbaum.

Marks, I. M (1969). Fears and phobias. London: Heinemann.

Marr, D. (1982). Vision. New York: Freeman.

McCarthy, R. A., \& Warrington, E. K. (1990). Cognitive neuropsychology: A clinical introduction. San Diego, CA: Academic Press.

McGuire, M. T., Marks, I., Nesse, R. M., \& Troisi, A. (1992). Evolutionary biology: A basic science for psychiatry? Acta Psychiatrica Scandinavica, 86, 89-96.
McGuire, M., \& Troisi, A. (1998). Darwinian psychiatry. New York: Oxford University Press.

McNally, R. J. (1987). Preparedness and phobias: A review. Psychological Bulletin, 101, 283-303.

Mealey, L. (1995). The sociobiology of sociopathy: An integrated evolutionary model. Behavioral and Brain Sciences, 18, 523-599.

Menzies, R. G., \& Clarke, J. C. (1995). The etiology of phobias: A nonassociative account. Clinical Psychology Review, 15, 23-48.

Menzies, R. G., \& Parker, L. (2001). The origins of height fear: An evaluation of neoconditioning explanations. Behaviour Research and Therapy, 39, 185-199.

Mesibov, G. B., Adams, L. W., \& Klinger, L. G. (1997). Autism: Understanding the disorder. New York: Plenum.

Millon, T. (1991). Classification in psychopathology: Rationale, alternatives, and standards. Journal of Abnormal Psychology, 100, 245-261.

Millon, T., \& Davis, R. D. (1996). Disorder of personality: DSM-IV and beyond (2nd ed.). New York: Wiley Interscience.

Mineka, S., \& Zinbarg, R. (1991). Animal models of psychopathology. In C. E. Walker (Ed.), Clinical psychology: Historical and research foundations (pp. 51-86). New York: Plenum.

Mithen, S. (1996). The prehistory of the mind: A search for the origins of art, religion and science. London: Phoenix.

Nagel, T. (1998). Reductionism and antireductionism. In The limits of reductionism in biology (Novartis Foundation Symposium 213, pp. 3-14). Chichester, England: Wiley.

Nesse, R. (1997). An evolutionary perspective on panic disorder and agoraphobia (pp. 73-83). In S. Baron-Cohen (Ed.), The maladapted mind: Classic readings in evolutionary psychopathology. Hove, UK: Psychology Press.

Nesse, R., \& Williams, G. (1997). Are mental disorders disease? In S. Baron-Cohen (Ed.), The maladapted mind: Classic readings in evolutionary psychopathology (pp. 1-22). Hove, UK: Psychology Press.

Nietzel, M. T., Bernstein, D. A., \& Milich, R. (1998). Introduction to clinical psychology. Englewood Cliffs, NJ: Prentice Hall.

Ohman, A. (1986). Face the beast and fear the face: Animal and social fears as prototypes for evolutionary analyses of emotion. Psychophysiology, 23, 123-145.

Pinker, S. (1997). How the mind works. New York: Norton.

Polaschek, D., Ward, T., \& Hudson, S. M. (1997). Rape and rapists: Theory and treatment. Clinical Psychology Review, 17, 117-144.

Poulton, R., Waldie, K. E., Menzies, R. G., Craske, M. G., \& Silva, P. A. (2001). Failure to overcome 
'innate' fear: A developmental test of the nonassociative model of fear acquisition. Behaviour Research and Therapy, 39, 29-43.

Premack, D., \& Woodruff, G. (1978). Does the chimpanzee have a theory of mind? The Behavioural and Brain Sciences, 4, 515-526.

Price, J. S. (1967). The dominance hierarchy and the evolution of mental illness. Lancet, 2, 243-246.

Price, J., Sloman, L., Gardner, R., Jr., Gilbert, P., \& Rohde, P. (1994). The social competition hypothesis of depression. British Journal of Psychiatry, 164, 309-315.

Profet, M. (1992). Pregnancy sickness as adaptation: A deterrent to maternal ingestion of teratogens. In J. Tooby \& L. Cosmides (Eds.), The adapted mind: Evolutionary psychology and the generation of culture (pp. 327-365). New York: Oxford University Press.

Reinecke, D. R., Newman, B., Kurtz, A. L., Ryan, C. S., \& Hemmes, N. S. (1997). Teaching deception skills in a game-play context to three adolescents with autism. Journal of Autism and Developmental Disorders, 27, 127-137.

Rose, H., \& Rose, S. (Eds.). (2000). Alas poor Darwin: Arguments against evolutionary psychology. London: Johnathon Cape.

Rose, M. R. (1998). Darwin's spectre: Evolutionary biology in the modern world. Princeton, $\mathrm{NJ}$ : Princeton University Press.

Ruse, M. (1985). Sociobiology: Sense or nonsense? (2nd ed.). Dordrecht, Holland: D. Reidel Publishing Co.

Seligman, M. E. P. (1971). Phobias and preparedness. Behavior Therapy, 2, 307-320.

Shallice, T. (1988). From neuropsychology to mental structure. New York: Cambridge University Press.

Shelton, R. C., Hollon, S. D., Purdon, S. E., \& Loosen, P. T. (1991). Biological and psychological aspects of depression. Behavior Therapy, 22, 201228.

Sterelny, K., \& Griffiths, P. E. (1999). Sex and death: An introduction to philosophy of biology. Chicago: University of Chicago Press.

Symons, D. (1979). The evolution of human sexuality. New York: Oxford University Press.
Symons, D. (1992). On the use and misuse of Darwinism in the study of human behavior. In J. H. Barkow, L. Cosmides, \& J. Tooby. (1992). The adapted mind: Evolutionary psychology and the generation of culture (pp. 327-365). New York: Oxford University Press.

Thornhill, R., \& Palmer, C. T. (2000). A natural history of rape: Biological bases of sexual coercion. Cambridge, MA: MIT Press.

Tooby, J., \& Cosmides, L. (Eds.). (1992). The adapted mind: Evolutionary psychology and the generation of culture. New York: Oxford University Press.

Wakefield, J. C. (1992). The concept of mental disorder: On the boundary between biological facts and social values. American Psychologist, 47, 373-388.

Wakefield, J. C. (1999). Evolutionary versus prototype analyses of the concept of disorder. Journal of Abnormal Psychology, 108, 374-399.

Ward, T., Keenan, T., \& Hudson, S. (2000). Understanding cognitive, affective, and intimacy deficits in sexual offenders: A developmental perspective. Aggression and Violent Behavior, 5, 41-62.

Watson, J. B., \& Rayner, R. (1920). Conditioned emotional reactions. Journal of Experimental Psychology, 3, 1-14.

Wilson, D. R. (1998). Evolutionary epidemiology and manic depression. British Journal of Medical Psychology, 71, 375-395.

Wilson, E. O. (1975). Sociobiology. Cambridge, MA: Harvard University Press.

Wolpe, J. (1958). Psychotherapy by reciprocal inhibition. Stanford, CA: Stanford University Press.

Wolpe, J., \& Lazarus, A. A. (1966). Behavior therapy techniques: A guide to the treatment of neuroses. New York: Pergamon Press.

Zeki, S. (1993). A vision of the brain. Boston: Blackwell Scientific.

Received February 21, 2001

Revision received August 20, 2001

Accepted August 27, 2001 